\title{
Impact of Anemia on In-Hospital, One-Month and One-Year Mortality in Patients with Acute Coronary Syndrome from the Middle East
}

\author{
Kadhim Sulaiman; Panduranga Prashanth; Ibrahim Al-Zakwani; Wael Al-Mahmeed; Ahmed Al-Motarreb; \\ Jassim Al Suwaidi; Haitham Amin; Nidal Asaad; Ahmad Hersi; Hussam Al Faleh; Shukri Al Saif; Alawi A. Alsheikh-Ali; \\ Jawad Al Lawati; and Khalid Al-Habib
}

\begin{abstract}
Aim: The aim of this study was to evaluate the impact of admission anemia on in-hospital, one-month, and one-year mortality in patients from the Middle East with acute coronary syndrome (ACS).

Methods: Data were analyzed from 7922 consecutive patients admitted to hospitals throughout six Middle-Eastern countries with the final diagnosis of ACS, as part of Gulf RACE II (Registry of Acute Coronary Events II). Anemia at admission was defined according to the World Health Organization definition $(<13 \mathrm{~g} / \mathrm{dL}$ in men and $<12 \mathrm{~g} / \mathrm{dL}$ in women). Analyses were conducted using univariate and multivariate statistical techniques.
\end{abstract}

Results: The median age of the cohort was 56 (48-65) years, with the majority being male (79\%). Anemia at admission was present in 224 I patients (28\%). Patients with anemia were more likely to have in-hospital complications including heart failure, recurrent ischemia, re-infarction, cardiogenic shock, stroke, and major bleed. Even after adjustment, anemia was still associated with mortality at in-hospital (odds ratio $[\mathrm{OR}]=1.7 \mathrm{I}, 95 \%$ confidence interval $[\mathrm{Cl}], 1.34-2.17 ; P<0.00 \mathrm{I}$ ), at one-month $(O R=1.34,95 \% \mathrm{Cl}, 1.06-1.7 \mathrm{I} ; \mathrm{P}=0.0 \mathrm{I})$, and at one-year $(\mathrm{OR}=1.22,95 \% \mathrm{Cl}, \mathrm{I} .0 \mathrm{I}-1.49 ; \mathrm{P}=0.049)$ postadmission with ACS.

Conclusions: Admission anemia in patients with ACS from six Middle-Eastern countries was strongly associated with mortality at in-hospital, one-month, and at one-year. Hence, admission anemia must be considered in the initial risk assessment of ACS patients along with other risk scores.

Keywords: Acute coronary syndrome; Anemia; Hemoglobin; Mortality; Middle East

\begin{abstract}
A these patients are reported to have poor in-hospital, shortterm, and long-term prognosis. ${ }^{1-9}$ In addition, the need for blood transfusion due to anemia in the setting of ACS is associated with higher short-term mortality. ${ }^{10}$ Furthermore, a low baseline hemoglobin level in ACS patients has been found to be an independent predictor of the risk of in-hospital major bleeding and risk of death and myocardial infarction at 30 days. $^{11}$
\end{abstract}

Low hemoglobin levels are common among the MiddleEastern adult population when compared to the Western population, mainly due to a high prevalence of hemoglobinopathies in the Arab population as well as nutritional deficiencies. ${ }^{12}$ There are currently no studies in the Middle East evaluating the influence of anemia in ACS patients. Hence, we undertook this study to evaluate the impact of admission anemia on in-hospital, 1-month, and 1 -year mortality in patients with ACS from the Middle East.
Corresponding Author: Dr. Kadhim Sulaiman; Department of Cardiology; Royal Hospital; PO Box 133I; Muscat PC-III; Sultanate of Oman; Phone: +968-99360025; Fax: +968-24697727; Email: kjsulaiman@hotmail.com
Received: July 9, 2011

Revised: October 20, 2011

Accepted: November 16, 2011

doi: $10.3121 / \mathrm{cmr} .2011 .1032$
Disclosure: The Gulf RACE registry is a Gulf Heart Association project supported by Sanofi-Aventis, Paris, France 
Table 1. Demographic and clinical characteristics of the study cohort stratified by anemia $(\mathrm{N}=7922)$.

\begin{tabular}{|c|c|c|c|c|}
\hline \multirow[b]{2}{*}{ Characteristic } & \multirow[b]{2}{*}{$\begin{array}{c}\text { All } \\
(\mathrm{N}=7,922)\end{array}$} & \multicolumn{2}{|c|}{ Anemia } & \multirow[b]{2}{*}{$\boldsymbol{P}$} \\
\hline & & $\begin{array}{c}\text { No } \\
(n=5681 ; 72 \%)\end{array}$ & $\begin{array}{c}\text { Yes } \\
(n=2241 ; 28 \%)\end{array}$ & \\
\hline \multicolumn{5}{|l|}{ Demographic } \\
\hline Age, median years (IQR) & $56(48-65)$ & $54(46-63)$ & $60(53-70)$ & $<0.001$ \\
\hline Female gender, n (\%) & $1,685(21 \%)$ & $989(17 \%)$ & $696(31 \%)$ & $<0.001$ \\
\hline \multicolumn{5}{|l|}{ Medical history, n (\%) } \\
\hline Diabetes mellitus & $3,132(40 \%)$ & $2,045(36 \%)$ & $1,087(49 \%)$ & $<0.001$ \\
\hline Hyperlipidemia & $2,596(33 \%)$ & $1,740(31 \%)$ & $856(38 \%)$ & $<0.001$ \\
\hline Hypertension & $3,744(47 \%)$ & $2,456(43 \%)$ & $1,288(57 \%)$ & $<0.001$ \\
\hline Chronic renal failure & $318(4.0 \%)$ & $86(1.5 \%)$ & $232(10.5 \%)$ & $<0.001$ \\
\hline Khat chew & $1,406(18 \%)$ & $997(18 \%)$ & $409(18 \%)$ & 0.326 \\
\hline \multicolumn{5}{|l|}{ Smoking status (includes hasheesh) } \\
\hline Never & $3,736(47 \%)$ & $2,417(43 \%)$ & $1,319(59 \%)$ & \\
\hline Former & $1,360(17 \%)$ & $953(17 \%)$ & $407(18 \%)$ & $<0.001$ \\
\hline Current & $2,826(36 \%)$ & $2,311(41 \%)$ & $515(23 \%)$ & \\
\hline Myocardial infarction & $1,524(19 \%)$ & $990(17 \%)$ & $534(24 \%)$ & $<0.001$ \\
\hline $\mathrm{PCl}$ & $726(9.2 \%)$ & $481(8.5 \%)$ & $241(10.8 \%)$ & 0.001 \\
\hline CABG & $335(4.2 \%)$ & $192(3.4 \%)$ & $143(6.4 \%)$ & $<0.001$ \\
\hline Stroke & $340(4.3 \%)$ & $179(3.2 \%)$ & $161(7.2 \%)$ & $<0.001$ \\
\hline \multicolumn{5}{|l|}{ Presentation, n (\%) } \\
\hline Systolic blood pressure $\leq 90 \mathrm{mmHg}$ & $394(5.0 \%)$ & $223(3.9 \%)$ & $171(7.6 \%)$ & $<0.001$ \\
\hline Heart rate $>100 \mathrm{bpm}$ & $1,410(18 \%)$ & $920(16 \%)$ & $490(22 \%)$ & $<0.001$ \\
\hline Killip score $>2$ & $666(8.4 \%)$ & $405(7.1 \%)$ & $261(11.6 \%)$ & $<0.001$ \\
\hline STEMI & $3,428(43 \%)$ & $2,634(46 \%)$ & $794(35 \%)$ & $<0.001$ \\
\hline \multicolumn{5}{|l|}{ GRACE risk score } \\
\hline Low & $3,067(39 \%)$ & $2,534(45 \%)$ & $533(24 \%)$ & $<0.001$ \\
\hline Medium & $3,053(39 \%)$ & $2,154(38 \%)$ & $899(40 \%)$ & 0.067 \\
\hline High & $1,701(21 \%)$ & $921(16 \%)$ & $780(35 \%)$ & $<0.001$ \\
\hline
\end{tabular}

Anemia was defined according to the WHO definition ( $<13 \mathrm{~g} / \mathrm{dL}$ in men and $<12 \mathrm{~g} / \mathrm{dL}$ in women).

IQR, Interquartile range; PCI, Percutaneous coronary intervention; CABG, Coronary artery bypass surgery; STEMI, ST elevation myocardial infarction; GRACE, Global Registry of Acute Coronary Events.

Analyses were conducted using Wilcoxon-Mann-Whitney test and Pearson's $\chi^{2}$ tests, whenever appropriate

\section{Methods}

This study was a retrospective analysis of ACS patients enrolled in a prospective registry, Gulf Registry of Acute Coronary Events - II (Gulf RACE-II), from six MiddleEastern countries. Gulf RACE-II design and methods are similar to Gulf RACE-I that has been previously reported. ${ }^{13}$ The Gulf RACE-II is a large prospective, multinational, multicenter registry of acute coronary events in the Middle East, focusing on the epidemiology, management practices, and outcomes of patients with ACS. Gulf RACE-II registry included consecutive patients above 18 years of age hospitalized with the final diagnosis of ACS (including unstable angina, ST-elevation myocardial infarction [STEMI], and non-STEMI) from 65 hospitals in six Middle-Eastern countries. Data were collected prospectively during the period between October 2008 and June 2009. The study recruited 7881 consecutive ACS patients from six adjacent Middle-Eastern Gulf countries: Bahrain, Saudi Arabia, Qatar, Oman, United Arab Emirates, and Yemen. There were no exclusion criteria. All hospitals included were either secondary or tertiary care hospitals and each hospital had coronary care units on-site, managed by either general physicians or cardiologists. On-site cardiac catheterization laboratories were available in $43 \%$ of hospitals.

A case report form for each patient with suspected ACS was completed upon hospital admission by assigned physicians and/or research assistants working in each hospital using standard definitions and completed throughout the patient's hospital stay. All case report forms were verified by a cardiologist then sent online (www.gulf-acs.com) to the principal coordinating center, where the forms were further 
Table 2. In-hospital outcome/procedure, medications, and mortality characteristics of the study cohort stratified by anemia $(\mathrm{N}=7922)$.

\begin{tabular}{|c|c|c|c|c|}
\hline \multirow[b]{2}{*}{ Characteristic } & \multirow[b]{2}{*}{$\begin{array}{c}\text { All } \\
(\mathrm{N}=7922)\end{array}$} & \multicolumn{2}{|c|}{ Anemia } & \multirow[b]{2}{*}{$\boldsymbol{P}$} \\
\hline & & $\begin{array}{c}\text { No } \\
(n=5681 ; 72 \%)\end{array}$ & $\begin{array}{c}\text { Yes } \\
(n=2241 ; 28 \%)\end{array}$ & \\
\hline \multicolumn{5}{|c|}{ In-hospital outcome/procedure, n (\%) } \\
\hline Congestive heart failure & $1,040(13 \%)$ & $584(10 \%)$ & $456(20 \%)$ & $<0.001$ \\
\hline Recurrent ischemia & $1,231(16 \%)$ & $785(14 \%)$ & $446(20 \%)$ & $<0.001$ \\
\hline Reinfarction & $172(2.2 \%)$ & $92(1.6 \%)$ & $80(3.6 \%)$ & $<0.001$ \\
\hline Cardiogenic shock & $457(5.8 \%)$ & $247(4.4 \%)$ & $210(9.4 \%)$ & $<0.001$ \\
\hline Stroke & $56(0.7 \%)$ & $28(0.5 \%)$ & $28(1.3 \%)$ & $<0.001$ \\
\hline Major bleed & $48(0.6 \%)$ & $20(0.4 \%)$ & $28(1.3 \%)$ & $<0.001$ \\
\hline $\mathrm{PCl}$ & $1,224(15 \%)$ & $992(17 \%)$ & $232(10 \%)$ & $<0.001$ \\
\hline CABG & $607(7.7 \%)$ & $428(7.5 \%)$ & $179(8.0 \%)$ & 0.498 \\
\hline \multicolumn{5}{|c|}{ Medications during $24 \mathrm{~h}$ of admission, $\mathrm{n}(\%)$} \\
\hline Aspirin & $7,794(98 \%)$ & $5,601(99 \%)$ & $2,193(98 \%)$ & 0.020 \\
\hline Clopidogrel & $6,036(76 \%)$ & $4,502(79 \%)$ & $1,534(68 \%)$ & $<0.001$ \\
\hline Beta blocker & $5,890(74 \%)$ & $4,313(76 \%)$ & $1,577(70 \%)$ & $<0.001$ \\
\hline Statin & $7,507(95 \%)$ & $5,437(96 \%)$ & $2,070(92 \%)$ & $<0.001$ \\
\hline ACEI & $5,599(71 \%)$ & $4,113(72 \%)$ & $1,486(66 \%)$ & $<0.001$ \\
\hline ARB & $394(5.0 \%)$ & $250(4.4 \%)$ & $144(6.4 \%)$ & $<0.001$ \\
\hline \multicolumn{5}{|c|}{ Medications at discharge, n (\%) } \\
\hline Aspirin & $7,350(93 \%)$ & $5,347(94 \%)$ & $2,003(89 \%)$ & $<0.001$ \\
\hline Clopidogrel & $5,359(68 \%)$ & $4,055(71 \%)$ & $1,304(58 \%)$ & $<0.001$ \\
\hline Beta blocker & $6,261(79 \%)$ & 4,624 (81\%) & $1,637(73 \%)$ & $<0.001$ \\
\hline Statin & $7,210(91 \%)$ & $5,261(93 \%)$ & $1,949(87 \%)$ & $<0.001$ \\
\hline ACEI & $5,635(71 \%)$ & $4,159(73 \%)$ & $1,476(66 \%)$ & $<0.001$ \\
\hline ARB & $536(6.8 \%)$ & 366 (6.4\%) & $170(7.6 \%)$ & 0.067 \\
\hline \multicolumn{5}{|l|}{ Mortality, n (\%) } \\
\hline In-hospital & $361(4.56 \%)$ & $178(3.13 \%)$ & $183(8.17 \%)$ & $<0.001$ \\
\hline 1-month & $572(8.2 \%)$ & 307 (6.1\%) & 265 (13.3\%) & $<0.001$ \\
\hline 1-year & $771(12.6 \%)$ & 431 (9.9\%) & $340(19.3 \%)$ & $<0.001$ \\
\hline
\end{tabular}

Anemia was defined according to the WHO definition ( $<13 \mathrm{~g} / \mathrm{dL}$ in men and $<12 \mathrm{~g} / \mathrm{dL}$ in women).

$\mathrm{PCl}$, Percutaneous coronary intervention; CABG, Coronary artery bypass surgery; ACEl, Angiotensin-converting enzyme inhibitor; ARB, Angiotensin receptor blocker.

*Percentages for 1-month and 1-year mortalities include only those who were alive at discharge and at 1 month and not lost to follow-up.

Analyses were conducted using Pearson's $\chi^{2}$ tests.

checked for potentially incorrect data before submission for final analysis. All the patients were evaluated for in-hospital clinical outcomes including mortality and were followed-up for mortality at 1 -month and 1 -year using telephone interviews. The diagnosis of the different types of ACS and definitions of data variables were based on the American College of Cardiology (ACC) clinical data standards. ${ }^{14}$ In addition, patients were stratified into low-, medium-, and high-risk groups based on tertiles of the calculated baseline Global Registry of Acute Coronary Events (GRACE) risk score (variables: age, Killip class, systolic blood pressure, ST segment deviation, cardiac arrest on admission, serum creatinine, raised cardiac markers, heart rate). ${ }^{15}$ The study cohort is categorized $(n=7922)$ on the basis of presence or absence of anemia at admission. Hemoglobin levels were measured within 60 minutes of admission. Anemia was defined according to the criteria of the World Health Organization (hemoglobin $<13 \mathrm{~g} / \mathrm{dL}$ in men and $<12 \mathrm{~g} / \mathrm{dL}$ in women). ${ }^{16}$ Accordingly, data were analyzed and compared for clinical characteristics, management, and in-hospital, 1-month and 1-year mortality. The study received ethical approval from the institutional ethical bodies in all participating countries.

Statistical Analyses

Descriptive statistics were used to summarize the data. For categorical variables, frequencies and percentages were reported. Differences between groups were analyzed using 
Table 3. In-hospital, 1-month, and 1-year mortalities stratified by admission anemia in patients with acute coronary syndrome (ACS).

\begin{tabular}{|c|c|c|c|c|c|c|}
\hline & In-hospital & & 1-month & & 1-year & \\
\hline $\operatorname{ACS}(\mathrm{N})$ & 7922 & & 7011 & & 6123 & \\
\hline No anemia (n) & 5681 & & 5024 & & 4359 & \\
\hline Anemia (n) & 2241 & & 1987 & & 1764 & \\
\hline Died, n (\%) & $361(4.56 \%)$ & & $572(8.16 \%)$ & & $771(12.6 \%)$ & \\
\hline No anemia, n (\%) & $178(3.13 \%)$ & \multirow{2}{*}{$P<0.001$} & 307 (6.11\%) & \multirow{2}{*}{$P<0.001$} & 431 (9.9\%) & \multirow{2}{*}{$P<0.001$} \\
\hline Anemia, n (\%) & $183(8.17 \%)$ & & $265(13.3 \%)$ & & 340 (19.3\%) & \\
\hline Lost-to-follow-up, n (\%) & $\mathrm{n} / \mathrm{a}$ & & $550(7.27 \%)$ & & $316(4.91 \%)$ & \\
\hline
\end{tabular}

Anemia was defined according to the WHO definition ( $<13 \mathrm{~g} / \mathrm{dL}$ in men and $<12 \mathrm{~g} / \mathrm{dL}$ in women).

Pearson's $\chi^{2}$ tests. For continuous variables, median and interquartile range were used to present the data while analysis was performed using Wilcoxon-Mann-Whitney test. The association of anemia on mortality (in-hospital, 1-month, and at 1-year) controlling for medication use, GRACE risk score, smoking status, diabetes mellitus, in-hospital percutaneous coronary intervention (PCI), and coronary artery bypass graft (CABG), were evaluated using multivariable logistic regression. To assess the incremental value of adding anemia, changes in the appropriateness of these models when anemia was added were compared. As recommended, ${ }^{17}$ the different approaches used were (1) changes in the Bayes information criterion (BIC) and Akaike information criterion (AIC), lower values for the BIC and AIC indicated better fit; and (2) changes in indexes of calibration (Pearson's $\chi^{2}$ and Hosmer-Lemeshow statistics) and discrimination (C-statistics). An a priori two-tailed level of significance was set at the 0.05 level. Statistical analyses were conducted using STATA version 11.1 (STATA Corporation, College Station, TX).

\section{Results}

Of 7930 patients with ACS enrolled in Gulf RACE-II, eight patients $(0.1 \%)$ were excluded from the present analysis due to missing admission hemoglobin values. The remaining 7922 patients represent the sample size for this study. Demographic and clinical characteristics of the cohort are

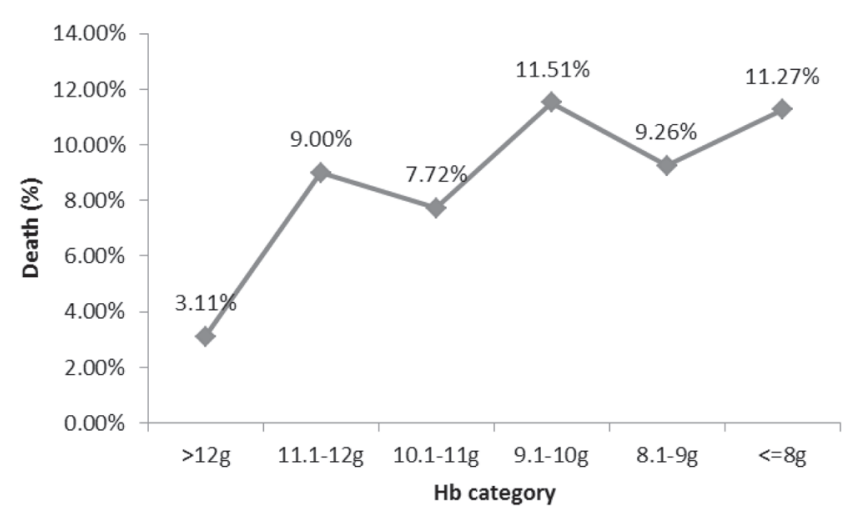

Figure 1. Graded response of hemoglobin $(\mathrm{Hb})$ on mortality. shown in table 1 . The median age of the cohort was 56 (48$65)$ years with the majority being male $(79 \%)$. The median hemoglobin level at admission was $13.8 \mathrm{~g} / \mathrm{dL}$ (range, $12.2 \mathrm{~g} /$ $\mathrm{dL}-15.0 \mathrm{~g} / \mathrm{dL})$. Anemia was present in 2241 patients (28\%).

Those ACS patients with anemia were more likely to be older and female and less likely to be current smokers. Patients with anemia were more likely to have significant comorbidities including diabetes, hyperlipidemia, hypertension, chronic renal failure, and stroke. They were also more likely to have had prior myocardial infarction and revascularization procedures (PCI and CABG). They were more likely to present with lower systolic blood pressure, higher heart rates, higher Killip class, and higher GRACE risk scores. Moreover, ACS patients with anemia were more likely to present with non-STEMI than STEMI.

As demonstrated in table 2, ACS patients with anemia were also more likely to experience in-hospital complications including congestive heart failure (CHF), recurrent ischemia, reinfarction, cardiogenic shock, stroke, and major bleed. However, they were less likely to have primary PCIs performed. Moreover, ACS patients with anemia were also less likely to receive recommended evidence-based medications than their counterparts without anemia, whether during hospital admission (within 24 hours) or at discharge. They were less likely to receive aspirin, clopidogrel, betablocker, statin, and angiotension converting enzyme inhibitors (ACEI) during discharge than those ACS patients without anemia. However, ACS patients with anemia were more likely to have used either aspirin or clopidogrel before admission than those who did not have anemia (53\% vs $36 \%$; $P<0.001)$. The overall in-hospital mortality rate was $4.56 \%$ (361 of 7922), while 1-month and 1-year mortalities were $8.2 \%$ (572 of 7011) and $12.6 \%$ (771 of 6123 ), respectively. Anemia was associated with higher in-hospital $(8.17 \%$ vs $3.13 \% ; P<0.001)$, 1 -month $(13.3 \%$ vs $6.11 \% ; P<0.001)$, and 1 -year $(19.3 \%$ vs $9.9 \% ; P<0.001)$ mortalities compared to those patients without anemia (table 3). Figure 1 represents graded response of anemia on mortality. Survival decreased significantly in a graded manner correlating with decreasing admission hemoglobin level. Higher levels of hemoglobin were associated with lower mortality $(3.11 \%$ vs $11.27 \%$ in 
Table 4. Impact of anemia on in-hospital, 1-month, and 1-year mortalities of the study cohort using multiple logistic regressions.

\begin{tabular}{|c|c|c|c|c|c|c|}
\hline \multirow{2}{*}{ Anemia } & \multicolumn{6}{|c|}{ Mortality } \\
\hline & \multicolumn{2}{|c|}{ In-hospital } & \multicolumn{2}{|c|}{ 1-month } & \multicolumn{2}{|c|}{ 1-year } \\
\hline OR $(95 \% \mathrm{Cl})$ & \multicolumn{2}{|c|}{$1.71(1.34-2.17)$} & \multicolumn{2}{|c|}{$1.34(1.06-1.71)$} & \multicolumn{2}{|c|}{$1.22(1.01-1.49)$} \\
\hline \multirow[t]{2}{*}{$P$ value } & $<0.001$ & & 0.016 & & 0.046 & \\
\hline & \multicolumn{6}{|c|}{ Anemia } \\
\hline Measures of fit & No & Yes & No & Yes & No & Yes \\
\hline LR $\chi^{2}$ test & $<0.001$ & $<0.001$ & $<0.001$ & $<0.001$ & $<0.001$ & $<0.001$ \\
\hline Pseudo $R^{2}$ & 0.164 & 0.171 & 0.360 & 0.362 & 0.264 & 0.265 \\
\hline $\mathrm{BIC}$ & -346 & -356 & $-1,203$ & $-1,120$ & $-1,038$ & $-1,033$ \\
\hline AIC & 2,291 & 2,273 & 2,332 & 2,328 & 3,178 & 3,176 \\
\hline C statistic & 0.81 & 0.82 & 0.84 & 0.84 & 0.80 & 0.80 \\
\hline \multicolumn{7}{|l|}{$P$ value } \\
\hline Pearson's GOF & $<0.001$ & $<0.001$ & 0.338 & 0.848 & 0.474 & 0.366 \\
\hline HL GOF & 0.860 & 0.418 & 0.017 & 0.032 & 0.259 & 0.031 \\
\hline
\end{tabular}

Anemia was defined according to the WHO definition ( $<13 \mathrm{~g} / \mathrm{dL}$ in men and $<12 \mathrm{~g} / \mathrm{dL}$ in women).

OR, Odds ratio; CI, Confidence interval; LR, Likelihood ratio; BIC, Bayesian information criterion; AIC, Akaike information criterion; HL, Hosmer \& Lemeshow; GOF, Goodness of fit.

The covariates in the models included medication (aspirin/clopidogrel, beta-blocker, statin, angiotensin-converting enzyme inhibitor/angiotensin receptor blocker) as well as GRACE risk score (derived from the following variables: age, systolic blood pressure, serum creatinine, heart rate, cardiac enzyme, Killip class, and cardiac arrest on admission), smoking status, diabetes mellitus, in-hospital percutaneous coronary intervention and coronary artery bypass graft.

patients with hemoglogin $>12 \mathrm{~g} / \mathrm{dL}$ compared to patients with hemoglobin $<8 \mathrm{~g} / \mathrm{dL}$, respectively).

Anemia was an independent predictor of mortality in-hospital, at 1-month, and at 1-year. The multiple regression models demonstrated that this relationship persisted even after adjustment. The adjusted odds ratio associated with anemia ranged from 1.01 to 2.17 for in-hospital, 1-month, and 1-year mortality (table 4). The addition of anemia improved both the discriminatory capacity and calibration of the models, with increased $C$ statistics as well as decreased BIC and AIC statistics. However, the impact of anemia on mortality was highest during hospital admission, but lessened after discharge as denoted by smaller changes in the goodness of fit statistics (table 4).

\section{Discussion}

In this study from Middle-Eastern countries, admission anemia in ACS patients proved to be independently associated with increased in-hospital, 1-month and 1-year mortality. Anemia was present in $28 \%$ of the ACS patients studied confirming that anemia is frequently found in patients with $\mathrm{ACS}$, although the prevalence varies widely between $10 \%$ to $30 \%$ depending on the definition used in various studies. ${ }^{1-9}$

In accordance with the findings linking anemia and poor clinical outcomes in ACS patients, this study demonstrated that ACS patients with anemia were more likely to be older, female, and associated with comorbidities like diabetes, hypertension, chronic renal failure, and stroke, ${ }^{1-9,18,19}$ thus identifying a high-risk population with poor hematopoetic reserve. They were more likely to present with lower systolic blood pressure, higher heart rates, and higher Killip class and GRACE risk scores. ${ }^{3,9,18,19}$ Sabatine et $\mathrm{al}^{3}$ reported hypotension, higher heart rate, and Killip class in STEMI patients with anemia. This was similar in our study, but was noted in all types of ACS patients, indicating that anemia in ACS as a poor prognostic factor is not confined to STEMI, but is universal among all types of ACS patients from the Middle East. In this study, ACS patients with anemia were more likely to present with non-STEMI than STEMI. The lower rate of anemia in STEMI patients may reflect younger age and less co-morbidities, including heart failure, when compared to non-STEMI patients. In the present study, anemic patients with ACS were more likely to experience in-hospital complications including $\mathrm{CHF}^{4,5,9}$ recurrent ischemia, ${ }^{2,3,19}$ reinfarction, ${ }^{3,8,11}$ cardiogenic shock, ${ }^{18}$ major bleed, ${ }^{11}$ and stroke. ${ }^{8,20}$ Furthermore, the presence of anemia in ACS patients doubled the risk of $\mathrm{CHF}$ and cardiogenic shock..$^{4,5,8,9,18}$ However, these findings should be interpreted in the context of the study's limitations. It is possible that anemia may be a marker for poor outcomes rather than a mediator, and that residual confounding factors (in the relationship between anemia and mortality) cannot be excluded.

There are multiple possible reasons for this worse clinical outcome and mortality in anemic patients with ACS. Reduction of myocardial oxygen supply along with increased myocardial oxygen demand (due to a compensatory higher stroke volume, 
tachycardia and decrease in blood viscosity required to maintain adequate systemic oxygenation) are the two most important causes by which anemia exerts its harmful effects on the myocardium. ${ }^{21}$ The compensatory mechanisms are mediated by sympathetic nervous system activation, which is deleterious in ACS. $^{6}$ Anemia in the presence of a fixed coronary artery stenosis decreases myocardial ability to increase cardiac output and thereby results in left ventricle dysfunction. This, along with exacerbation of ischemia by anemia in the post-ACS patient, may be responsible for the excess long-term mortality in this population. ${ }^{6}$ Anemia also leads to volume expansion, contributing to the development of CHF. Tissue hypoxemia results in lowering of systemic vascular resistance, leading to activation of the reninangiotensin-aldosterone and sympathetic nervous systems and subsequent volume expansion. Over time, fluid retention increases the cardiac workload, leading to ventricular remodeling including hypertrophy and dilation. ${ }^{19}$ Furthermore, these adaptive hemodynamic changes (ventricular dilatation and eccentric remodeling) causes higher oxygen consumption, increased diastolic wall stress, interstitial fibrosis, accelerated myocyte loss, and contribute to the development of $\mathrm{CHF},{ }^{7,21,22}$ which in turn causes hemodilution and precipitates further anemia.

Furthermore, in the present study, ACS patients with anemia were less likely to receive recommended evidenced-based medications as well as primary PCI. ${ }^{5,18,19}$ This may reflect the reluctance of physicians to initiate necessary medications or perform invasive procedures to avoid complications, especially bleeding complications and renal dysfunction. ${ }^{18}$ This could contribute to the poor prognosis in the anemic group. However, in the multivariable analyses, which included these treatments, anemia was independantly associated with excess mortality.

One of the main findings of the present study is that admission anemia during ACS was not only related to statistically significant higher in-hospital mortality, ${ }^{2,8,18}$ but also predicted 1-month ${ }^{1,3,11,18}$ and 1-year mortality. ${ }^{5-7,9,23-26}$ The multiple regression models showed that this relationship persisted even after adjustment with GRACE risk score. ${ }^{18}$ Sabatine et $\mathrm{al}^{3}$ did not find an increase in cardiovascular mortality, myocardial infarction, or recurrent ischemia in non-STEMI patients until hemoglobin values dropped below $10 \mathrm{~g} / \mathrm{dL}$. In this study, anemia $<13 \mathrm{~g} / \mathrm{dL}$ in men and $<12 \mathrm{~g} / \mathrm{dL}$ in women in a graded manner demonstrated increasing mortality, indicating that admission anemia per se (whether mild or severe) has a pronounced impact on survival in this MiddleEastern population. All the previous studies on this subject included a very defined subpopulation of patients with ACS and anemia ${ }^{1-9}$ or included varying durations of follow-up, either 30-days or 1-year or more. This study demonstrated that admission anemia (WHO-defined) in all types of ACS at three levels of follow-up (in-hospital, 1-month and 1-year) was independently associated with increasing mortality.
There are a few limitations of this study. The methods used in collecting data for the Gulf RACE are subject to limitations seen in a registry-type database. The causes of chronic anemia were not known, and the prognosis may vary according to the cause. There was no information regarding post-discharge hemoglobin level, which may also influence the long-term prognosis. Transfusions and additional bleeding events may account for some of the poor short- and long-term mortality. Furthermore, lack of predictor variables, as well as losses to follow-up at 1-month and 1-year could have affected the study's findings. Lastly, the GRACE risk score was proposed to estimate the risk of in-hospital mortality, not 1-month or 1 -year mortality. Additionally, a second GRACE risk score was not performed as it indicated 6-month mortality, not 1-month or 1-year mortality.

In conclusion, admission anemia in patients with ACS from six Middle-Eastern countries is strongly associated with adverse in-hospital clinical outcomes, as well as poor 1-month and 1-year mortality. Hence, admission anemia should be considered in the initial risk assessment of ACS patients along with other risk scores.

\section{References}

1. Lipsic E, van der Horst IC, Voors AA, van der Meer P, Nijsten MW, van Gilst WH, van Veldhuisen DJ, Zijlstra F. Haemoglobin levels and 30-day mortality in patients after myocardial infarction. Int J Cardiol 2005;100:289-292.

2. Bindra K, Berry C, Rogers J, Stewart N, Watts M, Christie J, Cobbe SM, Eteiba H. Abnormal haemoglobin levels in acute coronary syndromes. QJM 2006;99:851-862.

3. Sabatine MS, Morrow DA, Giugliano RP, Burton PB, Murphy $\mathrm{SA}$, McCabe CH, Gibson CM, Braunwald E. Association of haemoglobin levels with clinical outcomes in acute coronary syndromes. Circulation 2005;111:2042-2049.

4. Archbold RA, Balami D, Al-Hajiri A, Suliman A, Liew R, Cooper J, Ranjadayalan K, Knight CJ, Deaner A, Timmis AD. Haemoglobin concentration is an independent determinant of heart failure in acute coronary syndromes: cohort analysis of 2310 patients. Am Heart J 2006;152: 1091-1095.

5. Valeur N, Nielsen OW, McMurray JJ, Torp-Pedersen C, Kober L; TRACE Study Group. Anaemia is an independent predictor of mortality in patients with left ventricular systolic dysfunction following acute myocardial infarction. Eur J Heart Fail 2006;8:577-584.

6. Shu DH, Ransom TP, O'Connell CM, Cox JL, Kaiser SM, Gee SA, Rowe RC, Ur E, Imran SA. Anaemia is an independent risk for mortality after acute myocardial infarction in patients with and without diabetes. Cardiovasc Diabetol 2006;5:8.

7. Aronson D, Suleiman M, Agmon Y, Suleiman A, Blich M, Kapeliovich M, Beyar R, Markiewicz W, Hammerman H. Changes in haemoglobin levels during hospital course and long-term outcome after acute myocardial infarction. Eur Heart J 2007;28:1289-1296.

8. Nikolsky E, Aymong ED, Halkin A, Grines CL, Cox DA, Garcia E, Mehran R, Tcheng JE, Griffin JJ, Guagliumi G, Stuckey T, Turco M, Cohen DA, Negoita M, Lansky AJ, Stone GW. Impact of anaemia in patients with acute myocardial infarction undergoing primary percutaneous coronary intervention: analysis from the Controlled Abciximab and Device Investigation to Lower Late Angioplasty Complications (CADILLAC) trial. J Am Coll Cardiol 2004; 44:547-553. 
9. Anker SD, Voors A, Okonko D, Clark AL, James MK, von Haehling S, Kjekshus J, Ponikowski P, Dickstein K; OPTIMAAL Investigators. Prevalence, incidence, and prognostic value of anaemia in patients after an acute myocardial infarction: data from the OPTIMAAL trial. Eur Heart J 2009;30:1331-1339.

10. Rao SV, Jollis JG, Harrington RA, Granger CB, Newby LK, Armstrong PW, Moliterno DJ, Lindblad L, Pieper K, Topol EJ, Stamler JS, Califf RM. Relationship of blood transfusion and clinical outcomes in patients with acute coronary syndromes. JAMA 2004;292:1555-1562.

11. Bassand JP, Afzal R, Eikelboom J, Wallentin L, Peters R, Budaj A, Fox KA, Joyner CD, Chrolavicius S, Granger CB, Mehta S, Yusuf S; OASIS 5 and OASIS 6 Investigators. Relationship between baseline haemoglobin and major bleeding complications in acute coronary syndromes. Eur Heart J 2010;31:50-58.

12. Alhamdan NA, Almazrou YY, Alswaidi FM, Choudhry AJ. Premarital screening for thalassemia and sickle cell disease in Saudi Arabia. Genet Med 2007;9:372-377.

13. Zubaid M, Rashed WA, Al-Khaja N, Almahmeed W, Al-Lawati J, Sulaiman K, Al-Motarreb A, Amin H, Al-Suwaidi J, Al-Habib K. Clinical presentation and outcomes of acute coronary syndromes in the Gulf Registry of Acute Coronary Events (Gulf RACE). Saudi Med J 2008;29:251-255.

14. Cannon CP, Battler A, Brindis RG, Cox JL, Ellis SG, Every NR, Flaherty JT, Harrington RA, Krumholz HM, Simoons ML, Van De Werf FJ, Weintraub WS, Mitchell KR, Morrisson SL, Brindis RG, Anderson HV, Cannom DS, Chitwood WR, Cigarroa JE, Collins-Nakai RL, Ellis SG, Gibbons RJ, Grover FL, Heidenreich PA, Khandheria BK, Knoebel SB, Krumholz HL, Malenka DJ, Mark DB, Mckay CR, Passamani ER, Radford MJ, Riner RN, Schwartz JB, Shaw RE, Shemin RJ, Van Fossen DB, Verrier ED, Watkins MW, Phoubandith DR, Furnelli T. American College of Cardiology key data elements and definitions for measuring the clinical management and outcomes of patients with acute coronary syndromes. A report of the American College of Cardiology Task Force on Clinical Data Standards (Acute Coronary Syndromes Writing Committee). J Am Coll Cardiol 2001;38:2114-2130.

15. Granger CB, Goldberg RJ, Dabbous O, Pieper KS, Eagle KA, Cannon CP, Van De Werf F, Avezum A, Goodman SG, Flather MD, Fox KA; Global Registry of Acute Coronary Events Investigators. Predictors of hospital mortality in the global registry of acute coronary events. Arch Intern Med 2003;163:2345-2353.

16. World Health Organization. Iron deficiency anaemia: assessment, prevention, and control. A guide for programme managers. Geneva, Switzerland: World Health Organization; 2001. Available at: http://www.who.int/nutrition/publications/ micronutrients/anaemia iron deficiency/WHO NHD 01.3/ en/index.html . Accessed February 20, 2011.

17. Cook NR. Use and misuse of the receiver operating characteristic curve in risk prediction. Circulation 2007;115:928-935.

18. Meneveau N, Schiele F, Seronde MF, Descotes-Genon V, Oettinger J, Chopard R, Ecarnot F, Bassand JP; Reseau de Cardiologie de Franche Comte. Anaemia for risk assessment of patients with acute coronary syndromes. Am J Cardiol 2009; 103:442-447.

19. Rousseau M, Yan RT, Tan M, Lefkowitz CJ, Casanova A, Fitchett D, Jolly SS, Langer A, Goodman SG, Yan AT; Integrilin and Enoxaparin Randomized Assessment of Acute Coronary Syndrome Treatment (INTERACT) Trial Investigators. Relation between haemoglobin level and recurrent myocardial ischemia in acute coronary syndromes detected by continuous electrocardiographic monitoring. Am J Cardiol 2010;106:1417-1422.
20. Tanne D, Molshatzki N, Merzeliak O, Tsabari R, Toashi M, Schwammenthal Y. Anaemia status, haemoglobin concentration and outcome after acute stroke: a cohort study. BMC Neurol 2010;10:22.

21. Bassand JP. Impact of anaemia, bleeding, and transfusions in acute coronary syndromes: a shift in the paradigm. Eur Heart J 2007;28:1273-1274.

22. Nakamura R, Takahashi A, Yamada T, Miyai N, Irie H, Kinoshita N, Sawada T, Azuma A, Matsubara H. Erythropoietin in patients with acute coronary syndrome and its cardioprotective action after percutaneous coronary intervention. Circ J 2009;73:1920-1926.

23. Vis MM, Sjauw KD, van der Schaaf RJ, Koch KT, Baan J Jr, Tijssen JG, Piek JJ, de Winter RJ, Henriques JP. Prognostic value of admission haemoglobin levels in ST-segment elevation myocardial infarction patients presenting with cardiogenic shock. Am J Cardiol 2007;99:1201-1202.

24. Tsujita K, Nikolsky E, Lansky AJ, Dangas G, Fahy M, Brodie BR, Dudek D, Möckel M, Ochala A, Mehran R, Stone GW. Impact of anaemia on clinical outcomes of patients with ST-segment elevation myocardial infarction in relation to gender and adjunctive antithrombotic therapy (from the HORIZONS-AMI trial). Am J Cardiol 2010;105:1385-1394.

25. Kurek T, Lenarczyk R, Kowalczyk J, Swiatkowski A, Kowalski O, Stabryła-Deska J, Honisz G, Lekston A, Kalarus Z, Kukulski T. Effect of anaemia in high-risk groups of patients with acute myocardial infarction treated with percutaneous coronary intervention. Am J Cardiol 2010;105:611-618.

26. Cavusoglu E, Chopra V, Gupta A, Clark LT, Eng C, Marmur JD. Usefulness of anaemia in men as an independent predictor of two-year cardiovascular outcome in patients presenting with acute coronary syndrome. Am J Cardiol 2006;98:580-584.

\section{Author Affiliations}

Kadhim Sulaiman*; Panduranga Prashanth*; Ibrahim Al-Zakwanit; Wael Al-Mahmeed; Ahmed Al-Motarreb ${ }^{\S}$; Jassim Al Suwaidi ${ }^{\uparrow}$; Haitham Amin II ; Nidal Asaad"; Ahmad Hersi**; Hussam Al Faleh**; Shukri Al Saif †; Alawi A. Alsheikh-Alit, $\$$; Jawad Al Lawati"ף; Khalid Al-Habib**

*Department of Cardiology, Royal Hospital, Muscat, Oman tDepartment of Pharmacology and Clinical Pharmacy, College of Medicine and Health Sciences, Sultan Qaboos University, Muscat, Oman and Gulf Health Research,

Muscat, Oman

$¥$ Division of Cardiology, Sheikh Khalifa Medical City, Abu Dhabi, United Arab Emirates

§Faculty of Medicine, Sana's University, Sana'a, Yemen

"Hamad Medical Corporation, Doha, Qatar

\|Mohammed Bin Khalifa Cardiac Center, Manama, Bahrain

**King Fahad Cardiac Centre, King Saud University,

Riyadh, Kingdom of Saudi Arabia

HSaud Al-Babtain Cardiac Centre, Dammam, Saudi Arabia

$\S \S$ Tufts Clinical and Translational Science Institute, Tufts University School of Medicine, Boston, Massachusetts, USA

"I Department of Non-Communicable Diseases Surveillance and Control, Ministry of Health, Muscat, Oman 